\title{
Foreign Language Acquisition Anxiety and Project-Based Learning in Collaborative L2 Instruction: A Case Study
}

\author{
Elizandra Miguel \\ Lawton OK Chamber of Commerce, USA \\ William Carney \\ Department of Communication, English and Foreign Languages, Cameron University, USA
}

\begin{abstract}
This article discusses the experiences of an instructor-student collaboration in combining English as a Second Language instruction with a project-based model. It provides information about a year-long period of instruction that made use of extensive collaboration in language instruction for the creation of business documents geared to a specific purpose. The article suggests that such a project-based and collaborative approach to Foreign Language Learning might be useful in alleviating foreign language learning anxiety for advanced speakers of a second language. Additionally, the article discusses instruction performed via the Zoom platform. The use of platforms such as Zoom, or Skype, are becoming more ubiquitous as an instructional trend that pre-dates recent public health concerns, and this technology is discussed here in terms of the opportunities for collaborative learning and feedback it offers in a discipline that is still favors traditional face-to-face instruction. Although the experiences described here occurred in a non-academic setting with an instructor-student dyad, we suggest that it may be useful in academic settings with additional students and fewer collaborative opportunities to create highly specific objectives.
\end{abstract}

Index Terms-Business English, L2, online platforms, project-based learning

\section{INTRODUCTION}

The global pandemic has accelerated already-existing trends in education. Most notably, there is the turn toward online education with the development and increased use of programs such as Google Hangouts, Skype, or Zoom that allow for instruction that mimics, to varying degrees, what goes on in traditional face-to-face learning. These platforms are synchronous allowing participants to receive and provide real time instruction and feedback. Another trend involves a broadening of the educational enterprise though the use of these platforms. Students can take traditional college courses toward a degree, but they can also enroll in certificate programs that seek to teach specific job-related skills on a much shorter time frame. In addition, there are courses offered through companies such as Udemy that offer short-term and more narrowly focused instruction (e.g., a group of students reading and discussing Conrad's Heart of Darkness or Virgil's Aeneid for six weeks). These courses speak to the interests and specific needs of students.

One part of this latter trend involves also providing instruction in a much less formal setting and in subject matter areas that have not received a great amount of attention. The developing trend in focused, online learning has allowed for the adoption of less formal instruction and opportunities to teach subject matter areas that have not received much attention in more traditional settings. One of these areas is foreign language learning. Even pre-dating the pandemic, there has been a growing interest in using the internet to provide less formal (and not necessarily academic) instruction and support in language learning. Lanza and Gomes, Jr. (2020) discuss instances of collaborative foreign language learning on Instagram. Peeters (2018) discusses a similar use of Facebook for instruction and support in "communicative" English instruction. Al-Hasan (2021) discusses the opportunities for foreign language instruction on various online platforms to: (1) provide needed interaction during pandemic lockdowns, and (2) reduce learning anxiety through collaboration, and (3) continue ongoing instruction. Another aspect of this trend involves virtual instruction in a foreign language for employees and families of multinational corporations. An executive who relocates to Japan or who might be doing business virtually with Japanese colleagues might be eligible for a conversational Japanese program while an engineer and his or her family relocating to the United States from Brazil might be able to take advantage of English lessons. Companies such as LT-Global in Michigan contract with Fortune 500 companies to offer language instruction through a network of teachers and college instructors across the world. Because of health concerns, this instruction is largely provided virtually on the platforms mentioned above.

The two writers of the present article engaged in a student-teacher virtual instructional relationship over the course of a year. One of us (Elizandra) is a former Controller in a multinational corporation and the spouse of an executive from Brazil working in the United States. She received the opportunity for instruction through her spouse's company. She 
possesses a high degree of written and spoken English proficiency and has significant professional work history in Brazil as an auditor and as a Controller. The other author (William) is a college professor at a local public university who has developed and taught ESL programs for foreign students. The article discusses the goals and motivations behind this advanced English learning as well as the technological challenges inherent in the instruction. By discussing our roles in the instruction, we hope to shed some light on how this instruction worked for us and how it offers new possibilities for language learning. We understand, of course, that a single case study may not provide insights generalizable to other settings. Still, while we understand that our experience may not necessarily reflect those of other instructors or students, we nevertheless wish to share some insights about online foreign language instruction outside of an academic setting for advanced speakers and about teaching aspects of the language through an English for Specific Purposes (ESP) approach and through project-based learning (Park \& Hiver 2017).

Among the things we will discuss are the goals an advanced student brings to such an endeavor and the ways an instructor seeks to help the student attain these goals absent a physical classroom or academic setting. One of the key aspects of the case study we present here will be a discussion of foreign language learning anxiety. Mori \& Mori (2011) indicate that research on individual differences in second language acquisition often arise from non-linguistic and affective factors including motivation, anxiety, attitudes, and learner perceptions. Certainly, the alleviation of anxiety seems necessary for success in language learning. Bosman \& Hurd (2016) suggest that alleviation of anxiety can be best addressed through enhancing the learner's competence in pronunciation; we find that strategy necessary, but insufficient. We find greater promise in the use of an English for Specific Purposes (ESP) approach to English instruction and the use of project-based assignments for advanced language students (Park \& Hiver 2017). The autonomy afforded students by being able to make their own choices seems to be in accordance with Kao \& Cragie's (2013) "positive" approach to dealing with anxiety. Our experience lends some support to such an approach, although, as stated, we wonder about whether our experience can be replicated in academic settings. We hope this paper can provide an impetus for further and more formal investigation. Finally, we will discuss the challenges of providing such instruction on online platforms such as Skype and Zoom.

\section{THE PARTICIPANTS}

Elizandra came to the United States with her family when her husband transferred here from Sao Paolo to work in a manufacturing plant as an executive for his company. She spoke, read, and wrote in English at an advanced level, despite beginning English study at an age older than the "ideal." We begin our discussion with Elizandra discussing her previous English instruction. She did not begin English instruction until age 10, an age typically viewed as later than the ideal age for fluency in an L2 (second language). Elizandra describes her experiences as such:

I had my first contact with the English language in the public school in Brazil, at a time when public education was more concerned with quality than it is today (at least in much of our public discourse) but that did not seem to be the case with English instruction. I think that in 4 years of public school, the most I learned was the verb "to be." Instruction was very limited, and that certainly did not motivate me. My younger sister started earlier. While my sister did not have many opportunities for language instruction in Brazilian public schools, she was able to learn English and Spanish at an earlier age through private instruction.

Elizandra started work early to assist with the family's income and it did not take long for her to see the value of a second language:

It was only when I was 18 , when I worked two jobs and still bought and resold products to help with income, that I managed to start a private English course. I did it for 2 years and, whenever I could, I invested a larger amount of money in intensive courses so that I could speed up my learning. At that time, I didn't have much time to study outside the course, but I tried at least a few hours on weekends.

Friedrich \& Berns (2003) suggest that, because of the interest in Brazil in English instruction, there was the possibility that, without strict national standards, there would be a wide variance in the quality of instruction offered in various venues. At that time, there was little standardization and few studies of instructional effectiveness. Yet, as Elizandra found out, there were available resources even if they often did not leave ample time for someone working full time. Frustrated at being passed over for promotions and new opportunities, Elizandra decided that she would study abroad. "When I was almost 30, where time was still scarce due to working full time and trying to study English in a piecemeal fashion, I decided to immerse myself in English." She decided on a two-year plan and began three months of exchange in Australia. She remembers that, "I avoided having contact with people of the same nationality as me. I did so many things to insert myself in the language."

She says further that, "in Australia I studied at a school five hours a day learning the grammatical part, but at home I sat and reviewed all the content myself and received as much feedback as I could." English-language TV programs also helped to reinforce what was learned in other settings. Barrerra (2004) studied this phenomenon with children and found that multimedia exposure to the target language reinforces instruction.

Ultimately, Elizandra rose to the position of Controller in a multinational corporation where English was used as a common language across all nationalities and, all the while, she found opportunities for English practice whether on social media or in consuming mass media in English. After taking a break from her career to start a family, her husband 
took the opportunity to come to the US with his employer and, as an employee benefit, he and Elizandra were offered English instruction.

For William, working as a contractor for the company came through a series of events, beginning with the global pandemic. William had an on-going professional and personal interest in L2 instruction:

English as a Second Language has long been a scholarly and pedagogical interest. I developed a first-year writing program for non-native English speaking students at my university and was frequently offered opportunities in the community such as providing ACT preparation for high-school age children in a local Korean church.

He had developed student internships such as one in which US College students taught conversational and Business English to Kuwaiti soldiers stationed in the US for training. All these programs, however, were traditional face-to-face programs and involved group instruction and collaboration. As with McCarthy \& McCarten (2018), these projects involved using conversation and feedback as the main pedagogical method, with the group serving as a repository of linguistic knowledge.

With the advent of the global pandemic, these activities came to a halt. By chance, however, a company that provides language and educational services for a local manufacturing plant and their parent company contacted William about providing English instruction for the spouse (Elizandra) of one of their employees. An English speaker at a very advanced level, her goals were simply expressed as "getting better" at English and the early sessions involved a lot of more-or-less traditional spoken and written English lessons conducted on Skype and Zoom.

\section{INITIAL PROJECTS}

Elizandra's English proficiency was rated as "Advanced" using both the company's own assessment tools and the ACT English Proficiency Practice test. Vocabulary seemed to be the one area of any concern although her knowledge of Business terms in English was good. Woodrow (2018), in her book on course design for English for Specific Purposes, recommends a thorough needs analysis for students at any level of proficiency. She suggests that goals and objectives be defined collaboratively between the instructor and student. While we certainly attempted to devise an instructional plan, we were hampered in this regard by a conflict between William's vision and experience of instruction as an academic endeavor and Elizandra's as more of an English for Occupational Purposes (EOP) approach. Woodrow differentiates English for Business Purposes (EBP) from EOP and suggests that the former is more academic and general in its focus while EOP focuses on specific occupations and types of jobs.

Thus, for Elizandra, the course seemed to move slowly at first with little apparent focus until she expressed a desire to seek remote employment in accounting and auditing. Our difficulty up to this point stemmed in part from William's years in academic settings and Elizandra's career in a specific occupation. Additionally, as much as one hates to admit it, teachers are used to being in charge and true collaboration must be part of a deliberate choice. Clearly, we had to change the focus to address what Elizandra actually needed. Kim \& Bonk (2002) suggest that students and instructors from different cultural groups often find collaboration challenging even when there is both a need and an agreement that collaboration would be valuable. Indeed, online collaboration offers a widening of perspective for both student and instructor. We were fortunate in this case that Elizandra had clearly articulated "life goals" which certainly enhanced our search for collaboration and consensus.

The emerging desire to continue her career crystallized the focus for Elizandra. Weinstein (2006) discusses opportunities that arise from the life events of L2 learners, and in our case this new career goal provided an organizing principle for the instruction. The "curriculum" would focus on obtaining employment in Elizandra's field of expertise, starting with composing the documents she would need to submit to prospective employers and a published profile that placed her in an occupational community. She and William then collaboratively agreed to work on the following projects to address this desire:

- An English language resume;

- A LinkedIn profile;

- A PowerPoint presentation presenting information from the resume and details about personal experiences at work. This was developed to help with presenting concise information in an interview;

- An "elevator speech." Wesson (2013) recommends that professionals in technical fields practice a 60-second introduction to themselves, their qualifications, and achievements. Given the fact that fields such as engineering and accounting involve knowledge of technical details, workers in these fields should practice a short speech that illuminates interesting parts of their work histories designed primarily for hiring managers who are not themselves part of these fields.

Our curriculum became more project-based. Park \& Hiver (2017) advocate for the use of project-based second language learning as it is both process-oriented and results in the creation of tangible products, such as the online documents listed above. Further, such projects involve collaborative learning with participants acting as both creators and readers. Projects in second language learning can also lessen the anxiety that goes along with L2 learning and can create greater self-efficacy (Shin 2018), a subject covered in detail later in this paper. Polman, Stamatis, Boardman, \& Garcia (2018) suggest that the authenticity of project based foreign language learning creates learning experiences that are impossible to match in traditional L2 learning, at least for those learners with a high degree of proficiency. Equally 
important for Elizandra was the autonomy a project-based approach offered. She said, "I felt as if it puts the learner in control."

Indeed, for Elizandra, the projects that suggested more immediate use were the most engaging. "I didn't see what reason I had to do a PowerPoint. The resume and LinkedIn profile were things I could use right away," she offered. "I felt as if I needed something to start communicating on LinkedIn. It seemed a good place to start for job connections. Of course, when I got an interview, I went back to the PowerPoint for practice in making my answers more focused." We suggest that, in the experiences under discussion right now, the interest in finding employment and performing these activities in the setting of a non-academic learning environment allayed the anxiety inherent in L2 learning. MacIntyre \& Gregerson (2012) suggest that projects are necessarily collaborative as long as feedback is provided frequently and it seems here that working on a LinkedIn profile provided both instructor feedback as well as feedback from other users. For us, this project-based and collaborative approach served as a motivator. For Elizandra, the motivation seemed to supersede any anxiety created by the instruction.

\section{ANXIETY IN L2 LEARNING ENVIRONMENTS}

There is a great deal of anxiety inherent in learning a foreign language in any setting, and this has become the focus of a lot of research over the past two decades. Indeed, in our case, Elizandra spoke about feeling as if her accent often got in the way of effective communication. Martin \& Valdivia (2017) suggest that, in both face-to-face and online learning, instructor feedback is deemed by students to be the most important source of feedback but also the main source of both anxiety and, paradoxically, anxiety reduction for students. For Elizandra, the perceived differences in social power and expertise were sources of anxiety. In discussing this experience, she observed that:

My accent gets in the way and I am never sure that I am receiving the right amount of feedback. I say I want more but I worry that I'll be told that I have serious communication problems. There is embarrassment and I know it interferes with my learning to speak better English.

Working on projects allowed for a good amount of the feedback to come from the projects themselves and not directly from an instructor. Comparing her LinkedIn profile to those of others on the site, for example, provided authentic feedback and a sense of agency and "authorship."

Dewaele \& Alfawzan (2018) posit another strategy for anxiety reduction in L2 learning. Their empirical study suggests that the creation of an enjoyable environment for learning (what they term Foreign Language Enjoyment or FLE) is key to the alleviation of anxiety. Thus, if students find a particular project engaging and enjoyable, this experience seems to counteract anxiety. In our case, working on a LinkedIn profile as one of the early projects was quite serendipitous. Chang, Liu, \& Shen (2017) studied trust factors in LinkedIn and found that users report predominantly positive experiences with the platform. Elizandra was a regular user of the platform and not only enjoyed her time using it but also saw the potential it offered in an employment search.

To summarize, we found that our use of a project-based model offered the ability to determine what aspects of English were important in our case. Choosing the uses of English that were meaningful to Elizandra's life allowed her to choose the approach (EBP) and the individual projects she wanted. This autonomy and self-directedness seemed to have the effect of lessening any anxiety surrounding "correct" English use. Further, using the community on LinkedIn as another source of feedback gave this feedback a more "authentic" character.

The next aspect for discussion involves technological issues. Certainly, it helped that Elizandra was proficient in technology use. Woodrow (2018) urges caution in incorporating technology into EBP or EOP instruction as students and instructors might have very real differences in expertise. Having to learn a new platform or software while a student is attempting to improve L2 can itself be anxiety inducing. In our case, we used technological tools (Zoom and Skype) that we were both familiar with. We discuss concerns with technology in the next section of this article.

\section{TECHNOLOGY CONCERNS}

With the advent of the pandemic, most instruction previously offered in traditional formats migrated to online and "hybrid" platforms such as Skype and Zoom. Toyama \& Yamazaki (2021) found that students are relatively comfortable with English autonomous learning in a multimedia network environment, especially for online learning environments. Of course, their subjects were all engineering students with a high degree of technical expertise and a strong desire to learn English. Grewal (2002) suggests that, in the online world, English can be seen as the premier "network." Successful use of the internet involves English proficiency as most of the internet is in English. Still, when it comes to foreign language instruction, students taking face-to-face course are generally more satisfied with the course on several dimensions than are their online counterparts (Tratic, Urh \& Jereb 2017).

In our case, both Elizandra and William had a high degree of expertise and experience in navigating online courses and both of them had used Skype and Zoom extensively for communication purposes. The difficulties in the present case, however, stemmed from two things. First, William had little experience in creating and teaching a foreign language course online. While Zoom offered immediate feedback opportunities, similar in many ways to face-to-face instruction, he had never used it for ESL or any sort of language learning. Second, because of the pandemic, there were many instances of Zoom "lagging" even with faster internet connections. In our small city, there were frequent 
problems with Zoom (and to a lesser degree, Skype) due to the fact that schools and businesses were migrating much of their work to online platforms and people all over the community experienced frequent error messages regarding internet instability or even loss of service. Adedoyin \& Soykan (2020) note that, even in robust platforms such as Zoom, students often use browsers that may obstruct optimum learning. Still, for Elizandra, using Zoom and Skype led to a sense of accountability that was missing from asynchronous online instruction. She stated that, "I had to discipline myself to show up even when I didn't want to. I had to push myself but I had the reinforcement I needed."

\section{CONCLUSION}

We understand that our experience here is perhaps rather idiosyncratic. Further, ours was not the sort of experience typical in academic settings. For one thing, ours was one-on-one instruction. The results may have been quite different were there other students involved. Further, we were able to set (and re-set) goals on our own, something that never occurs in an academic setting. We found that the use of both EBP and project-based learning in a Zoom platform provided an instructional experience that focused on our objectives, was inherently motivating, and provided opportunities for immediate feedback. An approach like the one we employed could be used as an option for advanced L2 instruction as well as EOP instruction in specific areas such as business and nursing. It will be interesting to see if others can use EBP and project-based learning coupled with platforms such as Zoom in academic settings.

Collaboration is always a challenge for instructors in academic settings. They must balance student needs with the objectives of a particular course and of the institution in which that course is offered. Yet, if a degree of collaboration can be built into the course, online platforms can offer much in terms of instructional richness. Garrison (2006) recommends the phrasing of course objectives in the form of inquiry for best results. That is what we were able to do here, and this approach might be something that offers students opportunities for discovery and useful feedback on their L2 projects. Ewald (2008) argues for viewing students as "researchers" as both a way to allay anxiety and to achieve the best learning outcomes.

As a postscript, we have decided to embark on another project, this one seemingly more directly transferrable to the English as a Foreign Language classroom. Elizandra will write and record a series of podcasts on differences between Brazil and the United States, focusing on subjects such as differences in sentiment and etiquette toward the countries' flags, courtship and marriage rituals, and business communication. Otoshi \& Heffernan (2008) suggest that presentations, either face-to-face or online help L2 learners do three things: (1) practice vocal clarity, (2) use "correct" or expected uses of the target language, and (3) interact with an audience. Here, we will be using the record feature on Zoom plus the podcast software WavePad (NCH Software 2020). Again, the choice of a project with some immediate goals (in this case, to prepare for in-person networking) was something both of us can agree on. Podcasting is also something that William has incorporated into previous university writing courses so it seems as if this might be a project that offers much in the way of second language learning.

\section{REFERENCES}

[1] Al-Hasan, A. (2021). Effects of social network information on online language learning performance: A cross-continental experiment. International Journal of e-Collaboration (IJeC), 17(2), 1-16

[2] Barrera, R. M. (2004). A case for bilingual education. Scholastic Parent \& Child, 12(3), 72-73.

[3] Bosmans, D., \& Hurd, S. (2016). Phonological attainment and foreign language anxiety in distance language learning: A quantitative approach.” Distance Education, 37(3), 287-301. https://doi.org/10.1080/01587919.2016.1233049.

[4] Chang, S. E., Liu, A. Y., \& Shen, W. C. (2017). User trust in social networking services: A comparison of Facebook and LinkedIn. Computers in Human Behavior, 69, 207-217.

[5] Dewaele, J. M., \& Alfawzan, M. (2018). Does the effect of enjoyment outweigh that of anxiety in foreign language performance? Studies in Second Language Learning and Teaching, 8(1) 541-564.

[6] Friedrich, P., \& Berns, M. (2003). Introduction: English in South America, the other forgotten continent. World Englishes, 22(2), 83-90.

[7] Garrison, D. (2006). Online collaboration principles. Journal of Asynchronous Learning Networks, 10. https://doi.org/10.24059/olj.v10i1.1768.

[8] Grewal, D.S. (2008). Network power: The social dynamics of globalization. Yale.

[9] Kao, P. \& P. Craigie. (2013). Coping strategies of Taiwanese university students as predictors of English language learning anxiety." Social Behavior \& Personality: An International Journal, 41(3), 411-419. https://doi.org/10.2224/sbp.2013.41.3.411.

[10] Kim, K. \& Bonk C. (2002). Cross-cultural comparisons of online collaboration. Journal of Computer-Mediated Communication, 8 (1), https://doi.org/10.1111/j.1083-101.2002.tb00163.

[11] Lanza, E., \& Gomes, R. L. (2020). Family language policy: Foundations, theoretical perspectives and critical approaches. In A.C. Schalley \& S.A. Eisenchlas (Eds.), Handbook of home language maintenance and development: Social and affective factors (pp. 13-27). De Gruyter Mouton. https://doi.org/10.1515/9781501510175.

[12] MacIntyre, P. D., \& Gregersen, T. (2012). Emotions that facilitate language learning: The positive-broadening power of the imagination. Studies in Second Language Learning and Teaching, 2, 193-213.

[13] Martin, S., and Alvarez Valdivia, I. M. (2017). Students' feedback beliefs and anxiety in online foreign language oral tasks. International Journal of Educational Technology 14, 1-15. doi: 10.1186/s41239-017-0056-z

[14] McCarthy, M., \& McCarten, J. (2018). Now you're talking! Practising conversation in second language learning'. In C. Jones (Ed.), Practice in Second Language Learning (pp. 7-29). Cambridge. https://doi.org/10.1017/9781316443118. 
[15] Mori, Y., \& Mori, J. (2011). Review of recent research (2000-2010) on learning and instruction with specific reference to L2 Japanese. Language Teaching, 44(4), 447-484.

[16] NCH Software (2020). "Wave Pad." https://www.nch.com.au/wavepad/index.html.

[17] Otoshi, J., \& Heffernan, N. (2011). An analysis of a hypothesized model of EFL students' motivation based on selfdetermination theory. Asian EFL Journal, 13(3), 66-86.

[18] Park, H., \& Hiver, P. (2017). Profiling and tracing motivational change in project-based L2 learning. System. http://dx.doi.org/10.1016/j.system.2017.04.013

[19] Peeters, W. (2018). Applying the networking power of Web 2.0 to the foreign language classroom: A taxonomy of the online peer interaction process. Computer Assisted Language Learning, 31(8), 905-931.

[20] Polman, J. L., Stamatis, K., Boardman, A., \& Garcia, A. (2018). Authentic to whom and what? The role of authenticity in project-based learning in English language arts. International Society of the Learning Sciences, Inc. [ISLS].

[21] Shin, M. H. (2018). Effects of project-based learning on students' motivation and self-efficacy. English Teaching, 73(1), 95-114.

[22] Toyama, M., \& Yamazaki, Y. (2021). Classroom interventions and foreign language anxiety: A systematic review with narrative approach. Frontiers in Psychology, 12(80), 13-25.

[23] Tratnik, A., Urh, M., \& Jereb, E. (2017). Student satisfaction with an online and a face-to-face business English course in a higher education context. Innovations in Education and Teaching International, 56(1), 36-45. https://doi.org/10.1080/14703297.2017.1374875.

[24] Weinstein, G. (2006). "Learners' lives as curriculum": An integrative project-based model for language learning. In G.H. Beckett \& P.C. Miller (Eds.), Project-based second and foreign language education: Past, present, and future (pp. 159-168). Information Age Publishing.

[25] Wesson, R. D. (2013). Develop an elevator speech. ASEE Prism, 23(4), 21. http:// http://www.asee-prism.org/2013/page/8

[26] Woodrow, L. (2018). Introducing course design in English for specific purposes. Routledge.

Elizandra Miguel has much experience as a Controller for international companies in her native Brazil. She now works for the Lawton-Ft.Sill Chamber of Commerce in Oklahoma.

William Carney is a Professor at Cameron University in Oklahoma. He specializes in composition and EFL. 